\title{
Risk factors of frequent exacerbations in difficult-to-treat asthma
}

\author{
A. ten Brinke*, P.J. Sterk", A.A.M. Masclee ${ }^{\Uparrow}$, P. Spinhoven ${ }^{+}$, J.T. Schmidt ${ }^{\S}$, \\ A.H. Zwinderman ${ }^{f}$ K.F. Rabe ${ }^{\#}$ and E.H. Bel ${ }^{\#}$
}

ABSTRACT: Recurrent exacerbations are a major cause of morbidity and medical expenditure in patients with asthma. Various exogenous and endogenous factors are thought to influence the level of asthma control, but systematical data on the involvement of these factors in the recurrence of asthma exacerbations are scarce.

In this study, 13 clinical and environmental factors potentially associated with recurrent exacerbations were investigated in 136 patients with difficult-to-treat asthma. Patients with more than three severe exacerbations $(n=39)$ in the previous year were compared with those with only one exacerbation per year $(n=24)$. A systematic diagnostic protocol was used to assess 13 potential risk factors.

Factors significantly associated with frequent exacerbations included: severe nasal sinus disease (adjusted odds ratio (OR) 3.7); gastro-oesophageal reflux (OR 4.9); recurrent respiratory infections (OR 6.9); psychological dysfunctioning (OR 10.8); and obstructive sleep apnoea (OR 3.4). Severe chronic sinus disease and psychological dysfunctioning were the only independently associated factors (adjusted OR 5.5 and 11.7, respectively). All patients with frequent exacerbations exhibited at least one of these five factors, whilst $52 \%$ showed three or more factors.

In conclusion, the results show that recurrent exacerbations in asthma are associated with specific co-morbid factors that are easy to detect and that are treatable. Therapeutic interventions aimed at correcting these factors are likely to reduce morbidity and medical expenditure in these patients.

KEYWORDS: Asthma, asthma exacerbations, gastro-oesophageal reflux, psychology, sinusitis

I $\mathrm{n}$ the majority of patients, asthma can be reasonably well controlled with simple regimens of inhaled drugs. However, some patients suffer from frequent asthma exacerbations resulting in days of absence from work or school, the need for emergency treatment or admission to hospital. Such exacerbations are associated with considerable morbidity and account for a substantial proportion of the total costs of asthma [1]. Therefore, prevention of asthma exacerbations is an important goal in asthma therapy.

Despite the clinical and economic importance of asthma exacerbations, only a few studies have examined factors that may contribute to their recurrence. Emergency department visits and hospitalisation for asthma seem to be related to several psychosocial factors, such as lower socioeconomic status [2], inaccessibility of medical care [2] and co-existing psychiatric diseases [3]. In addition, patient characteristics that are associated with severe life-threatening asthma attacks include female sex, older age, smoking and noncompliance with recommended therapy [4-7]. Apart from these known patient characteristics and psychosocial circumstances, several endogenous and exogenous aggravating factors have been implicated in difficult-to-treat asthma [8-10]. However, it is unknown which factors contribute to the recurrence of exacerbations among these patients with poorly controlled disease.

Therefore, the aim of the present study was to evaluate clinical factors that may make asthma difficult to control and to identify potential risk factors of frequent asthma exacerbations. For this purpose, the prevalence of potential contributing factors (exposure to allergens, certain drugs or occupational sensitisers, severe nasal sinus disease, gastro-oesophageal reflux, recurrent respiratory tract infections, relative immunoglobulin deficiency, hyperthyroidism, obstructive sleep
AFFILIATIONS

Depts of ${ }^{\#}$ Pulmonary Diseases,

'Gastro-enterology and Hepatology, and

+Psychology, Leiden University,

Leiden,

${ }^{\S}$ Dept of Otorhinolaryngology,

Ziekenhuis Amstelland,

Amstelveen,

${ }^{f}$ Dept of Clinical Epidemiology and Biostatistics, Academic Medical

Center, Amsterdam, and

*Dept of Pulmonary Diseases,

Medical Center Leeuwarden,

Leeuwarden, The Netherlands.

CORRESPONDENCE

E.H. Be

Dept of Pulmonary Diseases

C3-P

Leiden University Medical Center

P.0. Box 9600

NL-2300 RC Leiden

The Netherlands

Fax: 31715154691

E-mail: E.H.D.Bel@lumc.nl

Received:

March 302005

Accepted after revision:

August 052005

SUPPORT STATEMENT

This study was supported by the Netherlands Asthma Foundation (grant 97.24). 
apnoea (OSA), hormonal influences, psychological dysfunctioning and poor inhaler technique) were systematically evaluated in a well-defined large group of patients with difficult-to-treat asthma, and compared in patients with and without frequent exacerbations with respect to these factors.

\section{MATERIALS AND METHODS Study subjects}

The present cross-sectional study was part of an extensive study on severe asthma performed in the Dept of Pulmonology of the Leiden University Medical Center (Leiden, The Netherlands) aimed at identifying risk factors of severity [11]. In this study, 152 patients with difficult-to-treat bronchial asthma [12], aged 18-75 yrs, were consecutively recruited from the outpatient pulmonary departments of 10 hospitals in the western region of The Netherlands. In total, 16 patients refused to participate, mainly due to lack of transport and time. The patients were all treated with $\geqslant 1,600 \mu \mathrm{g} \cdot$ day $^{-1}$ beclomethasone or equivalent and long-acting bronchodilators, and were all nonsmokers (smoking history $\leqslant 10$ pack-yrs). All patients were symptomatic and had experienced at least one severe exacerbation during the past year or were dependent on maintenance therapy with oral prednisone. The study was approved by the Hospital Medical Ethics Committee, and all patients gave informed consent.

\section{Study design}

At the first visit, patients' characteristics were documented according to a structured questionnaire, which was always carried out by the same investigator. A blood sample was then taken, patients' inhaler technique was checked, lung function measurements were performed and a self-report questionnaire on psychological functioning was completed. On a separate day, the presence or absence of severe nasal sinus disease was assessed by an independent ear nose and throat (ENT) specialist, based on symptoms, nasal endoscopy and standardised computed tomography (CT) scanning of the nasal sinus [13]. Finally, a 24-h oesophageal $\mathrm{pH}$ measurement was performed to assess pathological gastro-oesophageal reflux [14] in those patients who were able and willing to undergo this invasive measurement.

\section{Methods}

\section{Severe asthma exacerbations}

Severe asthma exacerbations were defined as periods of deteriorating symptoms or lung function requiring a course of oral corticosteroids, as judged by the patient's own chest physician [15]. The number of severe asthma exacerbations during the 12 months preceding the study was retrospectively assessed by asking the patients whether they had received one, two or at least three courses of oral corticosteroids.

\section{Lung function}

Forced expiratory volume in one second (FEV1) was assessed before and $30 \mathrm{~min}$ after the inhaled administration of $400 \mu \mathrm{g}$ salbutamol and $80 \mu \mathrm{g}$ ipratropium bromide and expressed as percentage of predicted value [16]. Reversibility in FEV1 was defined as follows [16]:

$$
\text { (FEV1post-FEV1baseline)/FEV1pred }
$$

Airway responsiveness to histamine (expressed as PC20 histamine) was measured using a standardised procedure [17].

\section{Potentially contributing factors}

In total, 13 factors potentially contributing to frequently recurring asthma exacerbations [10] were evaluated (table 1).

Atopic status was assessed by specific immunoglobulin $(\mathrm{Ig}) \mathrm{E}$ (score 0-4) to a panel of common aeroallergens (house dust mite and cockroach, grass and birch pollen, cat and dog dander, mugworth, and fungi), and food allergens (milk, soy, peanuts, fish, eggwhite and wheat; UniCAP®; Pharmacia \& Upjohn, Uppsala, Sweden). Patients were considered to be atopic if at least one of the specific IgEs to the aeroallergens showed a score of at least one. Ongoing allergen exposure was defined as being sensitised to house dust mite and/or pets (UniCAP score $\geqslant 3$ ) and living in a dust mite-rich environment

\section{TABLE 1}

Assessment of potential contributing factors to frequent exacerbations in difficult-to-treat asthma

\section{Ongoing allergen exposure}

Specific IgE to HDM, UniCAP $\geqslant 3$ and living in HDM-rich environment Specific IgE to any pet while having the same pet at home

\section{Food allergens}

UniCAP food mix $\geqslant 2$

Drugs

Present use of salicylates, NSAIDs, $\beta$-blockers or ACE inhibitors

Occupational (low molecular weight) sensitisers

Increased symptoms at work and exposure to known sensitiser, currently or in past

Severe chronic sinus disease

Indication for nasal sinus surgery by ENT specialist

Gastro-oesophageal reflux

Pathological reflux at 24-h pH measurement $\#$

Symptomatic improvement after a trial of proton-pump inhibitors

Recurrent (bacterial) respiratory infections

Requirement of $\geqslant 3$ antibiotic courses in last $2 \mathrm{yrs}$

Relative immune deficiency

Pathologically decreased levels of IgG subclasses, IgA subclasses or IgM"

Hyperthyroidism

Pathologically increased level of free thyroxin $\left(\mathrm{FT} 4>24 \mathrm{pmol} \cdot \mathrm{L}^{-1}\right)$ in peripheral blood"

Obstructive sleep apnoea syndrome

Documented abnormality at polysomnography or history of snoring with apnoeas $>10 \mathrm{~s}$

Hormonal influences

History of increased symptoms premenstrually, during pregnancy or at menopause

Psychological dysfunctioning

General Health Questionnaire-12 score $\geqslant 6^{+}$

Poor inhaler technique

$\geqslant 2$ errors out of 8 essential elements of proper medication inhalation ${ }^{+}$

Ig: immunoglobulin; HDM: house dust mite; NSAID: nonsteroidal antiinflammatory drug; ACE: angiotensin converting enzyme; ENT: ear nose and throat. ${ }^{\#}$ : 24-h pH measurement was performed in 39 patients; ': level below lower/above upper limit of normal values used in the current authors' laboratory ${ }^{+}$: for details about questionnaire/checklist see Methods section. 
(no mite-proof pillow and mattress encasements, no avoidance measures taken) or keeping a pet in the house. A high degree of sensitisation to food allergens (UniCAP score $\geqslant 3$ ) was considered an indicator of possible food allergy.

Symptomatic exposure to occupational sensitisers (allergens and/or low molecular weight sensitisers) and the use of drugs such as salicylates, nonsteroidal anti-inflammatory drugs, $\beta$ blockers or acetylcholine esterase inhibitors were also included in the analysis as potential asthma triggers.

Paranasal sinus disease was considered a potential aggravating factor if there was an indication for functional endoscopic sinus surgery, as judged by an independent ENT specialist. For this purpose, nasal endoscopy was performed (assessing the presence of post-nasal drip, septal deformation, purulent secretions, polyps and anatomical sinus ostial narrowing), in combination with standardised limited coronal sinus CT-scan scoring (assessing mucosal thickening in the sinuses, osteomeatal complexes and nasal cavities) [13].

Gastro-oesophageal reflux was considered to be present if demonstrated by a 24-h $\mathrm{pH}$ measurement of the oesophagus [14] or, in those patients unable or unwilling to undergo this invasive test, if severe reflux symptoms improved with a trial of proton-pump inhibitors and reoccurred after cessation of the anti-reflux medication.

Respiratory infections were defined as episodes of increased dyspnoea, cough and purulent sputum for which the attending physician or respiratory specialist had prescribed a course of antibiotic drugs.

Relative immune deficiency was considered in cases of pathologically decreased levels of $\operatorname{IgM}\left(\leqslant 0.6 \mathrm{~g} \cdot \mathrm{L}^{-1}\right), \quad \operatorname{IgA} A_{1}$ $\left(\leqslant 0.9 \mathrm{~g} \cdot \mathrm{L}^{-1}\right), \quad \operatorname{IgA} A_{2} \quad\left(\leqslant 0.15 \mathrm{~g} \cdot \mathrm{L}^{-1}\right), \quad \operatorname{IgG}_{1} \quad\left(\leqslant 4.2 \mathrm{~g} \cdot \mathrm{L}^{-1}\right), \quad \operatorname{IgG}_{2}$ $\left(\leqslant 1.2 \mathrm{~g} \cdot \mathrm{L}^{-1}\right), \operatorname{IgG}_{3}\left(\leqslant 0.23 \mathrm{~g} \cdot \mathrm{L}^{-1}\right)$ or $\operatorname{IgG}_{4}\left(\leqslant 0.12 \mathrm{~g} \cdot \mathrm{L}^{-1}\right)$.

Hyperthyroidism was present in cases with an elevated level of free thyroxin $\left(>24 \mathrm{pmol} \cdot \mathrm{L}^{-1}\right)$.

OSA was considered a potential contributing factor if the criteria were met by polysomnography, or in case of a history of daytime sleepiness and heavy snoring at night with frequent apnoea periods of $>10 \mathrm{~s}$ [18] reported by the partner.

Hormonal influences were considered significant if asthma started during pregnancy or at menopause, or in case of recurrent premenstrual attacks.

The General Health Questionnaire (GHQ) was used to evaluate each patient's psychological functioning. This is the most widely used screening test used to detect psychiatric disorders in medical practice. It measures the presence of nonpsychotic psychiatric disturbances, specifically anxiety and depression disorders. The short GHQ-12 version (score range 0-12) was used, with a score $\geqslant 6$ indicating possible psychiatric cases [19].

Skills in the use of a metered-dose or dry powder inhaler were evaluated by requesting patients to demonstrate their usual inhaler technique. Eight-step-scores specific for each inhaler device were adapted from a previously reported measure of inhaler use [20], with a score of at least two errors being indicative of poor inhaler technique.

\section{Analysis}

Differences in demographic characteristics between subgroups of patients were analysed using unpaired t-tests, Chi-squared analyses and nonparametric tests, wherever appropriate. To identify factors associated with frequent exacerbations, the subgroup of patients with the most (more than three) asthma exacerbations $(n=39)$ were compared with the patients having the least (only one) exacerbations $(n=24)$ in the 12 months preceding the study. The cut-off value of three exacerbations per year was chosen because patients with mild-to-moderate asthma rarely experience more than two exacerbations per year [15]. Patients on maintenance therapy with oral corticosteroids $(n=44)$ were excluded from the analysis, since, in these patients, the number of exacerbations according to the above definition could not be assessed.

In the logistic regression analyses, contrasts (absence or presence) in all potential contributing factors were considered for both patient groups. Odds ratios (OR) for patients with more than three exacerbations versus those with only one exacerbation as reference group were obtained by multiple logistic regression analyses, with one of the above factors as independent at a time in the model and corrected for possible confounders (age and asthma duration). In addition, a full multiple logistic regression analysis was applied with all significant contributing factors forced into the model.

Finally, the authors analysed whether the total number of the established contributing factors present in the patients was related to the number of exacerbations in the previous year by using Spearman rank correlation coefficients. A p-value of $<0.05$ was considered statistically significant.

\section{RESULTS \\ Prevalence of potential contributing factors}

In the 136 patients with severe asthma who participated in the study, the prevalence of potential contributing factors was assessed. Patient characteristics are given in table 2. These patients experienced a total of 244 severe asthma exacerbations and 72 hospital admissions with 895 hospitalised days in the

\begin{tabular}{|c|c|c|c|}
\hline \multirow[t]{2}{*}{ TABLE 2} & \multicolumn{3}{|c|}{$\begin{array}{l}\text { Patient characteristics of the total study } \\
\text { population and of patients included in the main } \\
\text { analysis }\end{array}$} \\
\hline & & $\begin{array}{l}\text { Total study } \\
\text { population }\end{array}$ & $\begin{array}{l}\text { Patients included in } \\
\text { main analysis }\end{array}$ \\
\hline \multicolumn{2}{|l|}{ Subjects $\mathbf{n}$} & 136 & 63 \\
\hline \multicolumn{2}{|l|}{ Age yrs } & $45.4 \pm 14.3$ & $41.5 \pm 14.1$ \\
\hline \multicolumn{2}{|l|}{ Female \% } & 69.9 & 73.0 \\
\hline \multicolumn{2}{|c|}{ Age at onset asthma yrs } & $16.5(0.5-68)$ & $18.0(0.5-68)$ \\
\hline \multicolumn{2}{|c|}{ Asthma duration yrs } & $18.0(2-73)$ & $16.0(2-57)$ \\
\hline \multicolumn{2}{|c|}{$\begin{array}{l}\text { Dose inhaled corticosteroids } \\
\mu \mathrm{g} \cdot \mathrm{day}^{-1 \#}\end{array}$} & $1600(1600-6400)$ & $1600(1600-4800)$ \\
\hline \multicolumn{2}{|c|}{ Maintenance oral steroids \% } & 32.6 & 0 \\
\hline \multicolumn{2}{|c|}{ Smoking history pack-yrs } & $0(0-10)$ & $0(0-10)$ \\
\hline
\end{tabular}




\begin{tabular}{lcc} 
TABLE 3 & $\begin{array}{l}\text { Prevalence of risk factors of frequent asthma } \\
\text { exacerbations in total study population and in } \\
\text { patients included in the main analysis }\end{array}$ \\
& $\begin{array}{l}\text { Total study } \\
\text { population }\end{array}$ & $\begin{array}{c}\text { Patients included in } \\
\text { the main analysis }\end{array}$ \\
\hline & & 63 \\
Subjects n & 136 & $61.9(48-71)$ \\
Recurrent respiratory infections & $58.1(50-66)$ & $49.2(39-61)$ \\
Gastro-oesophageal reflux & $49.3(41-58)$ & $500(34-62)$ \\
Severe chronic sinus disease & $45.5(36-55)$ & $35.0(23-49)$ \\
Ongoing allergen exposure & $38.5(30-47)$ & $33.3(18-47)$ \\
Relative immune deficiency & $31.5(19-44)$ & $29.7(17-44)$ \\
Hormonal influences ${ }^{*}$ & $30.0(20-40)$ & $28.6(18-39)$ \\
Occupational sensitisers & $27.9(20-36)$ & $18.4(12-31)$ \\
Psychological dysfunctioning & $20.4(13-28)$ & $14.8(10-32)$ \\
Poor inhaler technique & $20.4(13-28)$ & $6.3(3-29)$ \\
Obstructive sleep apnoea & $12.5(7-18)$ & $4.8(2-24)$ \\
Drugs & $9.6(5-15)$ & $10.0(3-16)$ \\
Food allergens & $9.4(4-14)$ & $1.6(1-6)$ \\
Hyperthyroidism & $1.5(1-4)$ & \\
\hline & &
\end{tabular}

12 months preceding the study. The three most prevalent contributing factors were recurrent respiratory infections, gastro-oesophageal reflux and severe sinus disease (table 3 ).

\section{Factors associated with frequent asthma exacerbations}

The analyses to identify risk factors of frequent severe exacerbations were performed in a subgroup of 63 patients, consisting of those with more than three exacerbations $(n=39)$ versus those with only one exacerbation $(n=24)$ in the previous year. Demographic characteristics of patients who were included or excluded from the analysis did not differ $(\mathrm{p}>0.05)$, except for oral corticosteroid usage, as expected $(\mathrm{p}<0.001$; table 3$)$.

The patients with recurrent exacerbations experienced a total of 186 severe exacerbations versus 24 in patients with only one exacerbation, 37 versus one hospital admission, 335 versus 10 hospitalised days, and 69 versus 15 emergency visits in the last 12 months (table 4). The patients with frequent exacerbations had a significantly younger age (mean 38 versus $47 \mathrm{yrs}$ ) and shorter asthma duration (median 12 versus $24.5 \mathrm{yrs}$ ) as compared with those without. In addition, the patients with frequent asthma exacerbations more often had a positive family history for asthma (59 versus 29\%; $p=0.02$ ) and a positive atopic status (69 versus $46 \% ; \mathrm{p}=0.07$ ). There was no significant difference between the groups in daily dose of inhaled corticosteroid or smoking history $(\mathrm{p}>0.3)$. Finally, bronchodilator reversibility and airway hyperresponsiveness were increased in the patients with more than three exacerbations as compared with the control group; however, this difference disappeared after correction for age and asthma duration.

In the logistic regression analyses, it appeared that the patients with frequent exacerbations in comparison with those without had an increased adjusted OR for a positive family history for asthma of 4.3 (95\% confidence interval (CI) 1.3-14.3) and that

\section{TABLE 4 Comparison of characteristics of patients with severe asthma with and without frequent exacerbations}

\begin{tabular}{|c|c|c|c|}
\hline & \multicolumn{2}{|c|}{ Exacerbations } & \multirow{2}{*}{ p-value } \\
\hline & $\geqslant 3$ & 1 & \\
\hline Subjects $n$ & 39 & 24 & \\
\hline Female \% & 79.5 & 62.5 & 0.14 \\
\hline Age yrs & $38.3 \pm 13.8$ & $46.7 \pm 13.1$ & 0.02 \\
\hline Asthma duration yrs & $12.0(2-53)$ & $24.5(4-57)$ & 0.01 \\
\hline Dose $\mathrm{ICS}^{\#} \mu \mathrm{g} \cdot \mathrm{day}^{-1}$ & $1600(1600-4800)$ & $1600(1600-4800)$ & 0.38 \\
\hline Smoking history pack-yrs & $0(0-10)$ & $0(0-9)$ & 0.65 \\
\hline $\begin{array}{l}\text { Positive family history } \\
\text { asthma \% }\end{array}$ & 59.0 & 29.2 & 0.02 \\
\hline Atopic \% & 69.2 & 45.8 & 0.07 \\
\hline Baseline FEV $1 \%$ pred & $72.9 \pm 23.6$ & $71.3 \pm 26.2$ & 0.82 \\
\hline $\begin{array}{l}\text { Reversibility FEV } 1 \% \\
\text { change }\end{array}$ & $11.6(0-44)$ & $7.5(-1-26)$ & 0.01 \\
\hline $\mathrm{PC}_{20}$ histamine $\mathrm{mg} \cdot \mathrm{mL}^{-1}$ & $0.29(0.02-8.0)$ & $2.73(0.02-8.0)$ & 0.07 \\
\hline Exacerbations last year & $4(3-7)$ & $1(1-1)$ & $<0.001$ \\
\hline Hospitalisations last year & $0(0-8)$ & $0(0-1)$ & 0.004 \\
\hline Emergency visits last year & $2(0-10)$ & $0(0-5)$ & 0.05 \\
\hline
\end{tabular}

Data are presented as mean \pm SD or median (range), unless otherwise stated ICS: inhaled corticosteroid; FEV1: forced expiratory volume in one second; \% pred: per cent predicted; PC20 histamine: airway responsiveness to histamine. \#: beclomethasone equivalent.

atopic patients had a 10.7-fold (95\% CI 2.3-49.3) increased odds for frequent asthma exacerbations as compared with nonatopic patients. In particular, the patients with specific IgE to house dust mite (adjusted OR (95\% CI) 6.9 (1.4-33.7)) and to cockroach (adjusted OR (95\%) 12.8 (1.4-119.2)) more often had recurrent exacerbations, whereas for the other specific allergens no significantly increased ORs were found.

The results of the logistic regression analysis on comorbid factors are summarised in table 5 and figure 1. Psychological dysfunctioning (OR 10.8), recurrent respiratory tract infections (OR 6.9), gastro-oesophageal reflux (OR 4.9), severe nasal sinus disease (OR 3.7) and OSA (OR 3.4) were significantly associated with frequent exacerbations. No significantly increased ORs were found for all the other potential contributing factors.

When analysing these five significantly contributing factors into one model, psychological dysfunctioning (adjusted OR (95\% CI) $11.7(1.2-114.3)$ ) and severe chronic sinus disease (adjusted OR (95\% CI) 5.5 (1.4-22.3)) were the only independent factors associated with frequent exacerbations. After correction for atopic status, the ORs even increased to 21.6 (95\% CI: 1.6-296) and 10.0 (95\% CI: 1.8-57.4), respectively. Similar results were obtained when re-analysing the data comparing the 68 patients with $\geqslant 2$ exacerbations with the 24 with one exacerbation (data not shown).

Spearman rank analysis showed a significant within-patient relationship between the number of contributing factors and the number of exacerbations per year (Rs 0.60; $\mathrm{p}<0.001$ ). 


\begin{tabular}{lc} 
TABLE 5 & $\begin{array}{l}\text { Odds ratios (ORs) for factors potentially } \\
\text { associated with frequent exacerbations in } \\
\text { difficult-to-treat asthma }\end{array}$ \\
& Adjusted OR $\mathbf{O R}^{\#} \mathbf{( 9 5 \%} \mathbf{~ C l )}$ \\
\hline Psychological dysfunctioning & $10.8(1.1-108.4)$ \\
Recurrent respiratory infections & $6.9(1.9-24.7)$ \\
Gastro-oesophageal reflux & $4.9(1.4-17.8)$ \\
Severe chronic sinus disease & $3.7(1.2-11.9)$ \\
Obstructive sleep apnoea & $3.4(1.2-10.4)$ \\
Hormonal influences & $2.8(0.5-15.8)$ \\
Hyperthyroidism & $1.9(0.2-19.6)$ \\
Occupational sensitisers & $0.7(0.2-2.1)$ \\
Poor inhaler technique & $0.6(0.1-2.9)$ \\
Food allergens & $0.6(0.1-3.5)$ \\
Ongoing allergen exposure & $0.5(0.2-1.3)$ \\
Relative immune deficiency & $0.4(0.1-1.7)$ \\
Drugs & $0.2(0.1-1.9)$ \\
\hline
\end{tabular}

Cl: confidence interval. ${ }^{*}$ : OR adjusted for age and asthma duration.

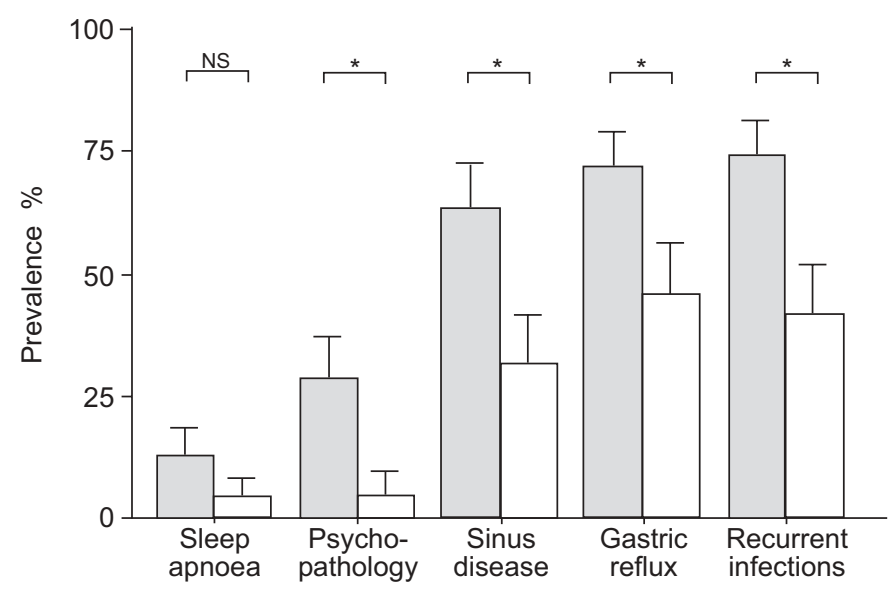

FIGURE 1. Comorbid factors associated with recurrent severe exacerbations. Patients with more than three severe exacerbations per year $(\square)$ had significantly more prevalent psychosocial dysfunctioning, severe sinus disease, gastric reflux or recurrent respiratory infections compared with patients with only one severe exacerbation ( $\square$ ). Error bars represent SE. NS: nonsignificant. *: $p<0.05$.

All patients with recurrent exacerbations showed at least one of the five established contributing factors (psychological dysfunctioning, severe nasal sinus disease, gastric reflux, recurrent respiratory infections or sleep apnoea), whereas three or more factors were identified in $52 \%$ of the patients (fig. 2). Remarkably, three out of these five factors were also amongst the most prevalent (table 4).

\section{DISCUSSION}

The results of the present study show that frequent exacerbations in difficult-to-treat asthma are invariably associated with one or more contributing factors other than asthma itself. Apart from younger age and shorter asthma duration, frequent

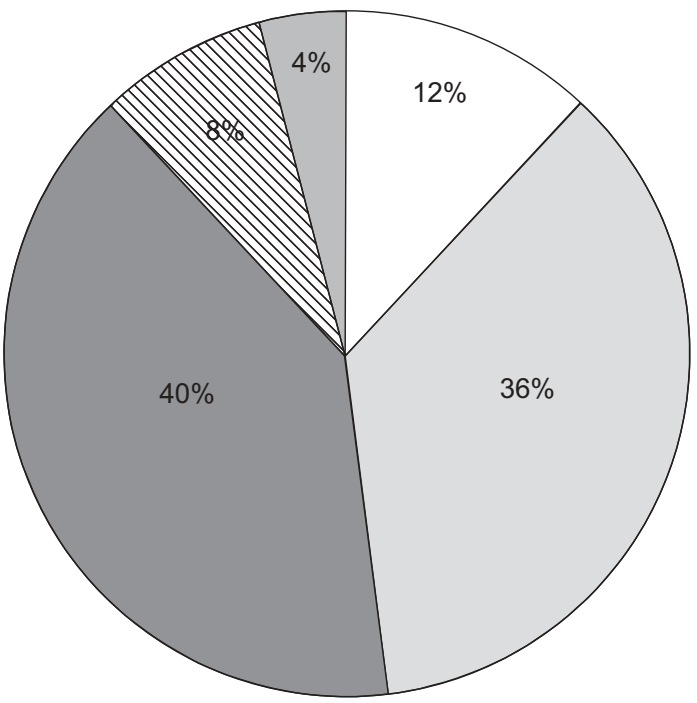

FIGURE 2. Frequency distribution of comorbid factors significantly associated with frequent severe exacerbations. In all patients with frequent exacerbations $(n=39)$, more than one factor (severe sinus disease, gastric reflux, recurrent respiratory infections, psychopathology or obstructive sleep apnoea) could be detected. $\square$ : one comorbid factor; $\square$ : two comorbid factors; $\mathbf{\square}$ : three comorbid factors; $\varangle$ : four comorbid factors; $\square$ : five comorbid factors.

exacerbations in these patients were strongly associated with psychological dysfunctioning (OR 10.8), recurrent respiratory tract infections (OR 6.9), gastro-oesophageal reflux (OR 4.9), severe nasal sinus disease (OR 3.7) and OSA (OR 3.4). Furthermore, atopic patients, in particular those with specific IgE to house dust mite or cockroach, had $>10$-fold increased odds for frequent exacerbations when compared with nonatopic patients. Psychological dysfunctioning and severe chronic sinus disease were the only independent contributing factors associated with frequent exacerbations, with adjusted ORs of 11.7 and 5.5, respectively. These findings emphasise the high prevalence of mostly unidentified contributing factors in difficult-to-treat asthmatic patients with frequent exacerbations, and suggest that treatment of these specific factors might result in better control of the disease.

Although risk factors of (near) fatal asthma attacks have been identified in earlier reports, the current authors are not aware of any study systematically evaluating factors in relation to the exacerbation frequency in difficult-to-treat asthma. Two studies not specifically focusing on asthma exacerbations showed that clinical improvement can be anticipated if patients with poorly controlled or difficult-to-treat asthma are submitted to a systematic evaluation protocol $[8,21]$, although one study failed to show an improvement in quality of life despite targeted treatment [8]. Another study in moderately severe asthma (425 exacerbations in 694 patients) showed female sex to be the main patient characteristic associated with an increased risk of severe exacerbations [15]. However, in the present study, investigating patients with more severe asthma (244 exacerbations in 92 patients), a clearcut clinical risk profile became apparent, while a female predominance was found in the whole group irrespective of the exacerbation rate. 
Due to the severity of the disease, a diagnosis of gastric reflux and sleep apnoea was established in some of the patients in this study by using clinical criteria instead of invasive measurements. This could have led to an underestimation of the prevalence of these two conditions. This is the more likely, since only $36 \%$ of the patients who underwent a $\mathrm{pH}$ measurement reported symptoms suggestive of reflux, whereas in $77 \%$ of these patients pathological reflux was demonstrated.

In the present study, a strong association was found between various contributing factors and frequent exacerbations, suggesting a causal relationship in this group of difficult-tocontrol patients. First, psychological dysfunctioning, as measured by a simple 12-item questionnaire, was strongly associated with recurrent asthma exacerbations. Several psychosocial factors have been shown to be related to poor asthma control and severe asthma attacks [22, 23]; however, longitudinal studies are needed to clarify whether psychological disturbances are the cause or consequence of the loss of control in asthma. If psychological disturbances are recognised and treated in these patients, the morbidity and exacerbation frequency of asthma might be significantly reduced [24]. Secondly, respiratory infections, in particular viral in origin, induce asthma exacerbations [25, 26]. However, bacteria, including the atypical, have also been linked to asthma exacerbations, in particular when sinusitis is present [27]. Thirdly, pathological gastro-oesophageal reflux is considered a potential trigger of asthma, even in the absence of oesophageal symptoms [28]. The mechanisms of acid-induced bronchoconstriction include a vaguely mediated reflex, increased airway responsiveness and micro-aspiration. Although there is some debate whether treatment for gastro-oesophageal reflux results in overall improvement in asthma, most authors agree that subgroups of patients may gain benefit [29]. Furthermore, chronic sinusitis has been suggested to play a causal role in difficult-to-control asthma. Clinical and experimental studies indicate that sinonasal inflammation can result in worsening of lower airway disease [30], potentially induced by post-nasal drip, nasobronchial reflex or inflammatory mediators. Proper medical and surgical management of sinusitis in the asthmatic patient has been shown to result in both improved sinonasal and asthmatic symptoms with fewer physician visits and decreased need for medication in several patients [31, 32]. Finally, snoring and obstructive apnoea have been suggested to trigger nocturnal asthma attacks and, indeed, improvement of asthma control after nasal continuous positive airway pressure therapy has been demonstrated in some unstable asthmatic patients [33].

In conclusion, one of the long-term aims of asthma management is to prevent exacerbations. This requires a better understanding of factors that contribute to the development of severe exacerbations. The present study, evaluating patients with difficult-to-treat asthma according to a systematic protocol, provides a clinical profile of the patients with frequent asthma exacerbations. In particular, psychopathology, chronic sinusitis, gastro-oesophageal reflux, (bacterial) respiratory infections and obstructive sleep apnoea appear to be associated with frequent exacerbations of asthma. It can be anticipated that rigorous treatment of these comorbid factors will result in less asthma exacerbations, which will greatly improve the quality of life of these difficult-to-control patients with asthma.

\section{ACKNOWLEDGEMENTS}

The authors would like to thank the chest physicians of the participating hospitals for their cooperation: P.I. van Spiegel, G. Visschers (Slotervaart Hospital, Amsterdam); A.H.M. van der Heijden (Rode Kruis Hospital, Beverwijk); B.J.M. Pannekoek (Reinier de Graaf Gasthuis, Delft); H.H. Berendsen, K.W. van Kralingen (Bronovo Hospital, Den Haag); H.G.M. Heijerman, A.C. Roldaan (Leyenburg Hospital, Den Haag); A.H.M. van der Heijden (Spaarne Hospital, Heemstede); H.C.J. van Klink (Diaconessenhuis, Leiden); C.R. Apap (St. Antoniushove, Leidschendam); and A. Rudolphus, K.Y. Tan (St. Franciscus Gasthuis, Rotterdam). They would also like to thank M.C. Timmers for technical assistance.

\section{REFERENCES}

1 Gendo K, Lodewick MJ. Asthma economics: focusing on therapies that improve costly outcomes. Curr Opin Pulm Med 2005; 11: 43-50.

2 Grant EN, Alp H, Weiss KB. The challenge of inner-city asthma. Curr Opin Pulm Med 1999; 5: 27-34.

3 Kolbe J, Fergusson W, Vamos M, Garrett J. Case-control study of severe life threatening asthma (SLTA) in adults: psychological factors. Thorax 2002; 57: 317-322.

4 Hartert TV, Speroff T, Togias A, et al. Risk factors for recurrent asthma hospital visits and death among a population of indigent older adults with asthma. Ann Allergy Asthma Immunol 2002; 89: 467-473.

5 Miller TP, Greenberger PA, Patterson R. The diagnosis of potentially fatal asthma in hospitalized adults. Patient characteristics and increased severity of asthma. Chest 1992; 102: 515-518.

6 Prescott E, Lange P, Vestbo J. Effect of gender on hospital admissions for asthma and prevalence of self-reported asthma: a prospective study based on a sample of the general population. Copenhagen City Heart Study Group. Thorax 1997; 52: 287-289.

7 Ulrik CS, Frederiksen J. Mortality and markers of risk of asthma death among 1,075 outpatients with asthma. Chest 1995; 108: 10-15.

8 Heaney LG, Conway E, Kelly C, et al. Predictors of therapy resistant asthma: outcome of a systematic evaluation protocol. Thorax 2003; 58: 561-566.

9 Robinson DS, Campbell DA, Durham SR, Pfeffer J, Barnes PJ, Chung KF. Systematic assessment of difficultto-treat asthma. Eur Respir J 2003; 22: 478-483.

10 Barnes PJ, Woolcock AJ. Difficult asthma. Eur Respir J 1998; 12: 1209-1218.

11 ten Brinke A, Zwinderman AH, Sterk PJ, Rabe KF, Bel EH. Factors associated with persistent airflow limitation in severe asthma. Am J Respir Crit Care Med 2001; 164: 744-748.

12 Chung KF, Godard P, Adelroth E, et al. Difficult/therapyresistant asthma: the need for an integrated approach to define clinical phenotypes, evaluate risk factors, understand pathophysiology and find novel therapies. ERS Task Force on difficult/therapy-resistant asthma. European Respiratory Society. Eur Respir J 1999; 13: 1198-1208. 
13 Newman LJ, Platts-Mills TA, Phillips CD, Hazen KC, Gross CW. Chronic sinusitis. Relationship of computed tomographic findings to allergy, asthma, and eosinophilia. JAMA 1994; 271: 363-367.

14 Masclee AA, de Best AC, de Graaf R, Cluysenaer OJ, Jansen JB. Ambulatory 24-hour pH-metry in the diagnosis of gastroesophageal reflux disease. Determination of criteria and relation to endoscopy. Scand J Gastroenterol 1990; 25: 225-230.

15 Tattersfield AE, Postma DS, Barnes PJ, et al. Exacerbations of asthma: a descriptive study of 425 severe exacerbations. The FACET International Study Group. Am J Respir Crit Care Med 1999; 160: 594-599.

16 Quanjer PH, Tammeling GJ, Cotes JE, Pedersen OF, Peslin R, Yernault JC. Lung volumes and forced ventilatory flows. Report Working Party Standardization of Lung Function Tests, European Community for Steel and Coal. Official Statement of the European Respiratory Society. Eur Respir J 1993; 6: Suppl. 16, 5-40.

17 Sterk PJ, Fabbri LM, Quanjer PH, et al. Airway responsiveness. Standardized challenge testing with pharmacological, physical and sensitizing stimuli in adults. Report Working Party Standardization of Lung Function Tests, European Community for Steel and Coal. Official Statement of the European Respiratory Society. Eur Respir J 1993; 6: Suppl. 16, 53-83.

18 Stradling JR, Davies RJ. Sleep. 1: Obstructive sleep apnoea/hypopnoea syndrome: definitions, epidemiology, and natural history. Thorax 2004; 59: 73-78.

19 Goldberg DP. The Detection of Psychiatric Illness by Questionnaire. London, Oxford University Press, 1972.

20 Williams MV, Baker DW, Honig EG, Lee TM, Nowlan A. Inadequate literacy is a barrier to asthma knowledge and self-care. Chest 1998; 114: 1008-1015.

21 Irwin RS, Curley FJ, French CL. Difficult-to-control asthma. Contributing factors and outcome of a systematic management protocol. Chest 1993; 103: 1662-1669.
22 Chetta A, Gerra G, Foresi A, et al. Personality profiles and breathlessness perception in outpatients with different gradings of asthma. Am J Respir Crit Care Med 1998; 157: 116-122.

23 Miles JF, Garden GM, Tunnicliffe WS, Cayton RM, Ayres JG. Psychological morbidity and coping skills in patients with brittle and non-brittle asthma: a case-control study. Clin Exp Allergy 1997; 27: 1151-1159.

24 Put C, van den Bergh O, Lemaigre V, Demedts $M$, Verleden G. Evaluation of an individualised asthma programme directed at behavioral change. Eur Respir J 2003; 21: 109-115.

25 Nicholson KG, Kent J, Ireland DC. Respiratory viruses and exacerbations of asthma in adults. BMJ 1993; 307: 982-986.

26 Johnston SL, Pattemore PK, Sanderson G, et al. Community study of role of viral infections in exacerbations of asthma in 9-11 year old children. BMJ 1995; 310: 1225-1229.

27 Kraft M. The role of bacterial infections in asthma. Clin Chest Med 2000; 21: 301-313.

28 Harding SM, Guzzo MR, Richter JE. The prevalence of gastroesophageal reflux in asthma patients without reflux symptoms. Am J Respir Crit Care Med 2000; 162: 34-39.

29 Gibson PG, Henry RL, Coughlan JL. Gastro-oesophageal reflux treatment for asthma in adults and children. Cochrane Database Syst Rev 2003; 2: CD001496.

30 Braunstahl GJ, Hellings PW. Allergic rhinitis and asthma: the link further unraveled. Curr Opin Pulm Med 2003; 9: 46-51.

31 Adams RJ, Fuhlbrigge AL, Finkelstein JA, Weiss ST. Intranasal steroids and the risk of emergency department visits for asthma. J Allergy Clin Immunol 2002; 109: 636-642.

32 Senior BA, Kennedy DW. Management of sinusitis in the asthmatic patient. Ann Allergy Asthma Immunol 1996; 77: 6-15.

33 Chan CS, Woolcock AJ, Sullivan CE. Nocturnal asthma: role of snoring and obstructive sleep apnea. Am Rev Respir Dis 1988; 137: 1502-1504. 